\title{
The Vulnerability of Children Lung to Environmental Hazards during the Sensitive Developmental Periods
}

Norma Helena Perlroth ${ }^{*}$ and Christina Wyss Castelo Branco ${ }^{2}$

'University Hospital Gaffrée Guinle, Department of Pediatrics, Pediatric Emergency Care, Federal University of the State of Rio de Janeiro, RJ, Brazil ${ }^{2}$ Department of Zoology, Institute of Biosciences, Federal University of the State of Rio de Janeiro, RJ, Brazil

Article Info

\section{Article Notes}

Received: March 18, 2018

Accepted: April 13, 2018

\section{*Correspondence:}

Dr. Norma H. Perlroth, University Hospital Gaffrée and Guinle, Department of Pediatrics, Federal University of the State of Rio de Janeiro, Rua Mariz e Barros, 775, CEP: 20270-002, Rio de

Janeiro - RJ - Brazil; Telephone: +55 2122397352

Email: norma.perlroth@gmail.com

(c) 2018 Perlroth NH. This article is distributed under the terms of the Creative Commons Attribution 4.0 International License.

\section{Keywords}

Fetal development

Child development

Environmental exposure

Environmental pollutants,

Lung diseases,

Health vulnerability and toxicity pathways.

\section{ABSTRACT}

Objective: The present study aims to identify the scientific evidence on the influence of the environment during the critical periods of children's lung development.

Data source: The search was performed in the Bireme database, using the terms: fetal development, child development, environmental exposure, environmental pollutants, lung diseases, health vulnerability and toxicity pathways in the LILACS, MEDLINE and SciELO systems.

Data synthesis: The vulnerability of children to respiratory diseases due to environmental hazards occurs because very specific physiological characteristics are found in this population. Exposure to toxic agents during the sensitive phases of child development can cause negative impacts to the normal physical lung. The caused effects are reflected in the increased prevalence on children morbidity with temporary or permanent pulmonary damage.

Conclusion: Understanding the effects of environmental exposures on the child lung and how they are established can contribute to the ultimate goal of prevention, i.e. to avoid, minimize or reduce the exposure of children to risk factors for their health.

Keywords: fetal development, child development, environmental exposure, environmental pollutants, lung diseases, health vulnerability and toxicity pathways.

\section{Introduction}

There are many problems facing children that contribute to the burden of environmental diseases in this population under 5 years. The survival of every child is still an unpostponable priority and varies enormously depending on where they were born and grow $^{1}$. In this sense, more than one million children die each year as a result of acute respiratory diseases, $60 \%$ of these deaths being related to environmental pollutants ${ }^{2}$. The number is astounding and cannot be ignored. Environmental risk factors, such as degraded ecosystems, environmental smoke, air pollution, and climate changes are the likely factors that cause changes in the health status of this population ${ }^{3,4}$. In low and medium-income nations, one of the most common environmental disorders, constituting major public health problem, is lower respiratory tract infections. Nevertheless in developed countries, the most prevalent diseases are allergy and asthma ${ }^{1,5}$. 
The Influence of the Environment during the Critical Periods of Pulmonary Development

The exposure to pollution on household indoor environments is a heterogeneous mix of hazardous components. The mix is the sum of pollutants of outdoor air and indoor sources, as tobacco and secondary domestic pollution ${ }^{6}$.

Tobacco smoke is a threat to children's health with adverse effects on their pulmonary function ${ }^{1,7,8}$. Data from a study by The National Health and Nutrition Examination Survey (NHANES), with children aged 3 to 19 years old, suggest a positive relationship between exposure to secondhand smoke and an elevated risk of pediatric hospitalization. Using serum cotinine (nicotine metabolite) as a biomarker for tobacco smoke, the researchers found that children with a high exposure to secondhand smoke (cotinine $\geq 3 \mathrm{ng} / \mathrm{mL}$ ), were 3.49 times more susceptible to an emergency pediatric hospitalization due to respiratory illnesses than children with no exposure to secondhand smoke 9 . According to another study, U.S. children exposed to the adverse effects of inhaling tobacco smoke may lead to 7 million school absences and 18 million days of limited activity ${ }^{10}$.

Secondhand smoking has a negative impact on children's health since the intrauterine stage, affecting infants' growth and developmentdue to a critical window of vulnerability to smoke exposure. Maternal smoking during pregnancy can result in more than 1,000 infant deaths annually ${ }^{11}$. The incidence of low birth weight in newborns of mothers who smoked during pregnancy was two times higher than those born to non-smoking mothers ${ }^{10,12}$. Smoking mothers are also responsible for an increased incidence of wheezing in babies ${ }^{13}$, ear infections, eye irritation ${ }^{14}$ and a history of respiratory diseases ${ }^{15-17}$ mainly among children under five years of age. In case control studies, children exposed to smoking show a chance nearly twice to develop the abovementioned diseases than those who are not exposed ${ }^{13,14,17,18,19}$. In addition, children living in crowded environments and poor housing conditions play a fundamental role in the causal chain of respiratory diseases ${ }^{20-22}$.

But even worse than exposing children to tobacco smoke is contaminating them with thirdhand smoking - THS ${ }^{23}$, which can cause changes to the DNA and cancer, as the nicotine residues provoke lesions that break the molecule bonds responsible for transmitting the genetic code $^{24}$. THS consists of residual tobacco smoke pollutants that remain on surfaces and dust and are re-emitted to the gas phase, or react with oxidizing agents and other compounds in the environment to obtain these secondary pollutants. Invisible, it is a threat because it is hidden in every corner of the house inhabited by smokers: furniture, curtains, pillows, mattresses, carpets and walls ${ }^{23}$.
According to $\mathrm{WHO}^{25}$, secondary domestic pollution due to the burning of solid fuel (wood, coal, manure, crop residue) on fires or traditional stoves is one of the top ten risks to health in the world, affecting children directly. The inefficient burn of those solid fuels releases a dangerous mixture of thousands of substances such as particulate matter, carbon monoxide, nitrous oxide, sulfuric oxides, formaldehyde, hydrocarbons and polycyclic organic matter, which includes carcinogenic substances such as benzopyrene ${ }^{26}$. The amount of smoke women and their young children inhale can be equal to that of two packs of cigarettes a day ${ }^{27}$. The WHO's research suggests that children under 5 years of age who inhale particulate matter (soot) from domestic air pollution may develop pneumonia, leading to premature deaths in more than $50 \%$ of cases ${ }^{25}$.

Air pollution in urban areas was identified as the driving factor in the prevalence of emergency care and hospitalizations in children with a higher occurrence of recurrent wheezing episodies ${ }^{28}$, as in asthma, bronchiolitis and pneumonia, as well as otitis, coryza and ocular irritation ${ }^{29}$.

Another type of pollutant harmful to children's health is the smoke from forest fires. It is made up of gases, such as water vapor, molecular nitrogen, sulfur dioxide $\left(\mathrm{SO}_{2}\right)$, carbon monoxide $(\mathrm{CO})$, carbon dioxide $\left(\mathrm{CO}_{2}\right)$, methane $\left(\mathrm{CH}_{4}\right)$, among others, and ash micro particles ${ }^{30}$. Children living near the fire-risk areas may suffer consequences to their health. Toxic agents like the total suspended particulate matter, inhalable particulate matter and nitrogen dioxide can cause undesirable effects through a combination of heat, pulmonary irritation, oxygen deprivation (asphyxia) and poisoning ${ }^{30}$.

Research indicates the causal link of climatic seasonality and children's respiratory symptoms. Some pathogenic respiratory viruses have a higher frequency in rainy seasons and during severe climate changes. Variations in rainfall and climate can cause precipitation of particulate matter in the atmosphere, increasing the prevalence of respiratory tract diseases in vulnerable children ${ }^{31}$.

\section{Phases of lung development}

A healthy lung growth, both before and after birth, is an important determinant in respiratory child health and essential to produce an appropriate airway system. During the intrauterine phase the existence of lungs, as breathing organs, are unnecessary. Even so, the lungs must be developed, in such a way as that they are immediately ready to function following birth ${ }^{29}$. Still in intrauterine life, the lungs are an important source of amniotic fluid. This fluid is produced daily $-15 \mathrm{ml}$ per kg of body weight, and can be swallowed or flowed out via the trachea and mouth ${ }^{32}$.

There are two stages to the development of the lungs: 
lung growth (structural development) and lung maturation (functional development). Adequate lung growth function at birth depends upon a mature surfactant system and lungs of normal size and can be influenced by physical factors $^{33,34}$ (Table.1).

\section{Structural lung development}

There are five stages of structural lung development (Figure 1). They occur at a progressive time during the gestational period, and there is no absolute agreement about the weeks that comprise each phase, varying between fetuses ${ }^{35}$.

\section{Biochemical maturation}

Lung maturation with its full functionality is primarily a biochemical process and is under the control of a number of different endogenous hormones, such as glucocorticoids, which play an important role in the development of the fetal lung ${ }^{32}$. The production of pulmonary surfactant (a lipoprotein complex) is very relevant. Surfactant is responsible for the decrease in surface tension within alveoli and prevents collapse of alveoli during exhalation. Premature babies are more prone to respiratory problems such as lung collapse, if they are born prior to the adequate formation of surfactant $t^{32,36}$.

Table 1: Physical factors linked with adequate lung growth.

\begin{tabular}{|l|l|}
\hline \multicolumn{1}{|c|}{ Adequate intrathoracic } & \multicolumn{1}{c|}{ Physical compression decrease intrathoracic space and impede lung } \\
\hline space & growth \\
\hline Adequate presence of lung liquid & $\begin{array}{l}\text { The volume of lung fluid is maintained by the activity of the upper airway which controls } \\
\text { the resistance to efflux of fluid out of the lung and trachea during non-breathing peri- } \\
\text { ods, and by diaphragmatic movement associated with fetal breathing movements. }\end{array}$ \\
\hline Adequate amount of amniotic fluid & $\begin{array}{l}\text { Oligohydramnios retards lung growth possibly by lung compression affecting fetal } \\
\text { breathing movements }\end{array}$ \\
\hline $\begin{array}{l}\text { Fetal breathing movements of normal incidence } \\
\text { and amplitude }\end{array}$ & $\begin{array}{l}\text { Fetal breathing movements stimulate lung growth, possibly by stretching } \\
\text { the pulmonary tissue and do induce small changes in phasic flow }\end{array}$ \\
\hline $\begin{array}{l}\text { Normal balance of volumes and pressures within } \\
\text { the potential airways and airspaces }\end{array}$ & $\begin{array}{l}\text { In the fetus, tracheal pressure greater than amniotic pressure and greater than pleural } \\
\text { pressure, produces a distending pressure that may promote lung growth. }\end{array}$ \\
\hline Adapted fromath
\end{tabular}

Adapted from Kitterman, 1988; Rothstein, 2004.

Stages of prenatal lung development

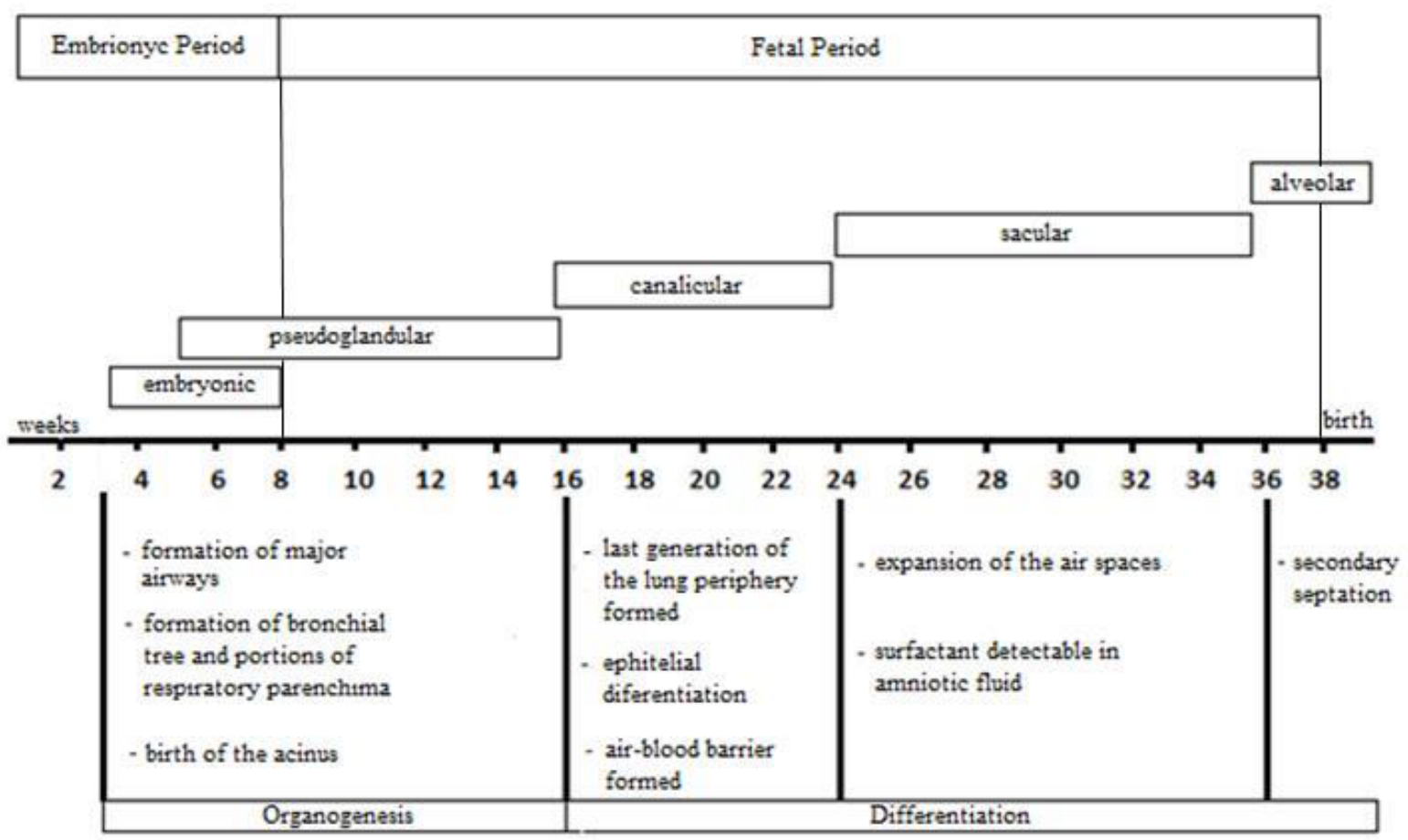

Adapted from Universities of Fribourng, Lauseanne and Bern (Switzerland), 2006.

Figure 1: Stages of prenatal lung development. 


\section{Children's particular characteristics}

The vulnerability of children respiratory diseases to environmental hazards occurs because very specific physiological characteristics are found in this population. The determining risk factors are: fragility in intrauterine life; immaturity of the lung; development and growth in progress; unconsciousness of health risks and threats and child breathe in greater proportion to their body weight ${ }^{29}$. Lung development is not complete at birth ${ }^{37}$ and proceeds through proliferation of pulmonary alveoli and capillaries until the age of 2 years. Thereafter, the lung grows through alveolar expansion until 5-8 years of age ${ }^{38}$.

Infants and young children breathe comparatively more air than an adult at rest, even though the adult has a major lung capacity, which corresponds to about 6.5 liters, whereas in a child this capacity is about 2 liters ${ }^{39,40}$. Considering the body weight, the air volume passing through the airways of the child at rest is twice of that in adults, under similar conditions ${ }^{41}$. An infant has three times the ventilation per minute than an adult, and a 6-year-old child has twice this volume ${ }^{42}$. Babies who were born prematurely may be more vulnerable to environmental aggression due to pulmonary immaturity ${ }^{39}$. Accordingly, the effects caused by air pollutants in young children may result in a potentially significant obstruction to their airways, whereas it can only produce a light response on an adult ${ }^{29}$.

As children breathe more air and tend to be more physically active than adults, inhaling toxic gases may compromise their pulmonary function or exacerbate pre-existing conditions, increasing the incidence of acute respiratory infections in this population, expressed as increased hospitalizations and school absenteeism ${ }^{40}$.

Gases inhaled by the child are partially eliminated by the exhaled $\mathrm{air}^{43}$. The processes involved are diffusion by alveolar membranes, which will depend on the liquid medium where the harmful compound is diluted (blood) and the gas phase (alveolar air). These contaminants are eliminated at a rate inversely proportional to the retention in the blood ${ }^{43}$. Thus, poorly soluble volatile substances in the blood are rapidly eliminated, while the very soluble ones in the blood are slowly excreted by expired air. Nitrous oxide, which has low blood solubility, is rapidly excreted, while ethanol, which is very soluble in water, is slowly excreted in the lungs ${ }^{43}$. Other examples of this last type of substances are gases such as carbon monoxide (CO), nitrogen dioxide $\left(\mathrm{NO}_{2}\right)$, ozone $\left(\mathrm{O}_{3}\right)$, sulfur dioxide $\left(\mathrm{SO}_{2}\right)$, lead, mercury, particulate matter in suspension (dust, smoke and aerosols), plus some alcohols and pesticides ${ }^{29,30}$.

Pulmonary disorders resulting from exposure to toxic contaminants occur because children have no control over the environment in prenatal and postnatal periods, including the quality of the air they breathe, the water they drink, and the food they eat ${ }^{44}$. Children have peculiar habits and are unaware of risks and threats to their health, and this contributes to adverse effects due to a higher exposure to pollutants ${ }^{29}$.

\section{Conclusion}

The review has clearly shown the causal link of environment hazards on children pulmonary health during critical periods of development: in-utero, when exposure to second-hand smoking has a negative impact on lung maturation and also on the anthropometric measures of newborns ${ }^{45}$; in infants, when exposure to toxic agents at home affects the respiratory tract and increases the prevalence of pulmonary infections. During this period of life, children stay longer at home, in direct contact with environmental pollutants ${ }^{46}$; and in preschool years, when respiratory diseases are more common, with higher risks of temporary or permanent damage to the normal physical lung and, consequently, to their current and future health ${ }^{29}$.

Knowledge of the effects of environmental exposure on the lungs of children and how they are caused can contribute to the ultimate goal of prevention, i.e. to avoid, minimize or reduce the exposure of children to risk factors.

\section{Conflict of interests}

The authors certify that there is no conflict of interest with any financial/research/academic organization, with regards to the content/research work discussed in the manuscript.

\section{References}

1. Perlroth NH, Branco CWC. Children's Environment in Brazil: From Domestic (Indoor) to Regional Threats. Int J pediatr Child Care. 2017; 2 (2): 1 - 28.

2. United Nations Children's Fund. Commitment to Child Survival: A Promise. Progress Report 2014. Executive Summary (in Portuguese). Brazil: UNICEF. 2014; 1 - 4.

3. Mello-da-Silva CA, Fruchtengarten L. Environmental chemical hazards and child health. J Pediatr. 2005; 81 (5): s 205 - s 211.

4. Quiroga D. La historia ambiental pediátrica. In: Manual desalud ambiental infantil. Chile: LOM Editors. 2009; 27 - 31.

5. Pawankar R. Allergic diseases and asthma: a global public health concern and a call to action. World Allergy Organ J. 2014; 7 (1): 12.

6. Le Cann P, Bonvallot N, Glorennec P et al. Indoor environment and children's health: recent developments in chemical, biological, physical and social aspects. Int J Hyg Environ Health. 2011; 215 (1): 1 - 18.

7. DiFranza JR, Aligne A, Weitzman M. Prenatal and Postnatal Environmental Tobacco Smoke Exposure and Children's Health. Pediatrics. 2004; 113: 1007 - 1015.

8. Currie J. Pollution and Infant Health. Child Dev Perspect. 2013; 7 (4): $237-242$.

9. Merianos AL, Jandarov RA, Mahabee-Gittens EM. Secondhand Smoke Exposure and Pediatric Healthcare Visits and Hospitalizations. Am J Prev Med. 2017; 53 (4): 441-448.

10. Raja D, Sultana B. Health Risk of Environmental Tobacco Smoke (ETS). IJAHSP. 2013; 11 (2): 1 - 6. 
11. U.S. Department of Health and Human Services. The Health Consequences of Smoking-50 Years of Progress: A Report of the Surgeon General. Atlanta: U.S. Department of Health and Human Services, Centers for Disease Control and Prevention, National Center for Chronic Disease Prevention and Health Promotion, Office on Smoking and Health, 2014.

12. Zhang L, González-Chica DA, Cesar JA, et al. Maternal smoking during pregnancy and anthropometric measurements of newborns: a population-based study in southern of Brazil. Cad Saude Publica. 2011; 27 (9): 1768 - 1776.

13. Schvartsman C, Farhat SCL, Schvartsman SPHN. Parental smoking patterns and their association with wheezing in children. Clinics. 2013; 68 (7): 934 - 939.

14. Coelho AS, Rocha AS, Jong LC. Outcomes of secondhand smoking in children. Cienc Cuid Saude. 2012; 11 (2): 294 - 301.

15. Gonçalves-Silva RMV, Valente JG, Lemos-Santos MGF, et al. Household smoking and respiratory disease in under-five children. Cad Saude Publica. 2006; 22 (3): 579 -586.

16. Carvalho LMT, Pereira EDBP. Respiratory morbidity among passive smoking children. J Pneumologia. 2002; 28 (1): 8 - 14.

17. Pereira EDB, Torres L, Macêdo J, et al. Effects of environmental tobacco smoke on lower respiratory system of children under 5 years old. Rev Saude Publica. 2000; 34 (1): 39 - 43.

18. Casagrande RRD, Pastorino AC, Souza RGL, et al. Asthma prevalence and risk factors in schoolchildren of the city of São Paulo, Brazil. Rev Saude Publica. 2008; 42 (3): 517-523.

19. Macedo SEC, Menezes AMB, Albernaz E, et al. Risk factors for acute respiratory disease hospitalization in children under one year of age. Rev Saude Publica. 2007; 41 (3): 351 - 358.

20. Prietsch SOM, Fischer GB, César JA, et al. Acute lower respiratory illness in under-five children in Rio Grande, Rio Grande do Sul State, Brazil: prevalence and risk factors. Cad Saude Publica. 2008; 24 (6): 1429 - 1438.

21. Gonçalves-Silva RMV, Valente JG, Lemos-Santos MGF, et al. Household smoking and respiratory disease in under-five children. Cad Saude Publica. 2006; 22 (3): 579 -586.

22. Prietsch SOM, Fischer GB, César JA, et al. Acute disease of the lower airways in children under five years of age: role of domestic environment and maternal cigarette smoking. J Pediatr. 2002; 78 (5): $415-422$.

23. Matt GE, Quintana PJ, Zakarian JM, et al. When smokers move out and non-smokers move in: residential thirdhand smoke pollution and exposure. Tob Control. 2011; 20 (1): e1.

24. Ramírez N, Özel MZ, Lewis AC, et al. Exposure to nitrosamines in thirdhand tobacco smoke increases cancer risk in non-smokers. Environ Int. 2014; 71: 139 - 47.

25. World Health Organization. Household air pollution and health. Fact sheet $\mathrm{N}^{\circ} 292$. WHO; Geneva. 2014.

26. Bruce N, Perez-Padilla R, Albalak R. Indoor air pollution in developing countries: a major environmental and public health challenge. Bull World Health Organ. 2000; 78 (9): 1078 - 92.

27. Bruce N, Perez-Padilla R, Albalak R. The health effects of indoor air pollution exposure in developing countries. Introduction. WHO; Geneva. 2002; 9 - 12.
28. Prietsch SOM, Fischer GB, César JA, et al. Risk factors for recurrent wheezing in children under 13 years old in the South of Brazil. Rev Panam Salud Publica. 2006; 20 (5): 331 - 337.

29. Perlroth NH. 2016. Environmental Interference in the Health of the Brazilian Child: Current Panorama and Challenges (in Portuguese). Doctoral dissertation. Program in Nursing and Biosciences, Federal University of the State of Rio de Janeiro, RJ, Brazil.

30. World Health Organization. Humanitarian Health Action. Ambient (outdoor) air quality and health. Fact sheet n.313. WHO; Geneva. 2014.

31. Rosa AM, Ignotti E, Botelho C. Respiratory disease and climatic seasonality in children under 15 years old in a town in the Brazilian Amazon. J Pediatr. 2008; 84 (6): 543 - 549.

32. Universities of Fribourng, Lauseanne and Bern (Switzerland). Human Embryology. Module 18. Respiratory Tract. Introduction. 2006.

33. Kitterman JA. Physiological factors in fetal lung growth. Can J Physiol Pharmacol. 1988; 66 (8): 1122 - 8.

34. Rothstein P. Lung Development. Columbia University. New York. 2004; 12: $1-12$.

35. DiFiore JW, Wilson JM. Lung Development. Seminars in Pediatric Surgery, 1994; 3 (4): 221 - 232.

36. Lyra PPR, Diniz EMA. The importance of surfactant on the development of neonatal pulmonary diseases. Clinics. 2007; 62 (2): $181-190$.

37. Le Cann P, Bonvallot N, Glorennec P, et al. Indoor environment and children's health: recent developments in chemical, biological, physical and social aspects. Int J Hyg Environ Health. 2011; 215 (1): $1-18$.

38. Selevan SG, Kimmel CA, Mendola P. Identifying critical windows of exposure for children's health. Environ Health Perspect. 2000; 108 (Suppl 3): $451-55$.

39. Perlroth NH, Branco CWC. Current knowledge of environmental exposure in children during the sensitive developmental periods. J Pediatr. 2017; 93 (1): 17 - 27.

40. Pinkerton KE, Joad JP. The mammalian respiratory system and critical windows of exposures for children's health. Environ Health Perspect. 2000; 108: s457 - 62.

41. Landrigan PG, Garg A. Children are not little adults. In: PronczukGarbino J. Editor. Children's health and the environment. A global perspective. WHO; Geneva. 2005; 3 - 16.

42. World Health Organization. Children's Health and the Environment. Children are not little adults. WHO; Geneva. 2008.

43. Ruppenthal JE. Toxicology (in Portuguese). Industrial Technical College of Santa Maria. Federal University of Santa Maria. E-Tec Network. Brazil. 2013.

44. Wigle DT. Environmental Threats to Child Health: Overview. In: Child Health and the Environment. New York: Oxford University Press. 2003; 1 - 26.

45. Salihu HM, Wilson RE. Epidemiology of prenatal smoking and perinatal outcomes. Early Hum. Dev 2007; 83: 713 - 20.

46. Öberg M, Jaakkola MS, Woodward A, et al. Worldwide burden of disease from exposure to second-hand smoke: a retrospective analysis of data from 192 countries. Lancet. 2011; 377:139-4. 